\title{
Membrane lipid raft organization during cotton fiber development
}

\author{
XU Fan ${ }^{\dagger}$, SUO Xiaodong ${ }^{\dagger}$, LI Fang, BAO Chaoya, HE Shengyang, HUANG Li and LUO Ming
}

\begin{abstract}
Background: Cotton fiber is a single-celled seed trichome that originates from the ovule epidermis. It is an excellent model for studying cell elongation. Along with the elongation of cotton fiber cell, the plasma membrane is also extremely expanded. Despite progress in understanding cotton fiber cell elongation, knowledge regarding the relationship of plasma membrane in cotton fiber cell development remains elusive.

Methods: The plasma membrane of cotton fiber cells was marked with a low toxic fluorescent dye, di-4ANEPPDHQ, at different stages of development. Fluorescence images were obtained using a confocal laser scanning microscopy. Subsequently, we investigated the relationship between lipid raft activity and cotton fiber development by calculating generalized polarization (GP values) and dual-channel ratio imaging.

Results: We demonstrated that the optimum dyeing conditions were treatment with $3 \mu \mathrm{mol} \cdot \mathrm{L}^{-1}$ di-4-ANEPPDHQ for $5 \mathrm{~min}$ at room temperature, and the optimal fluorescence images were obtained with $488 \mathrm{~nm}$ excitation and 500-580 $\mathrm{nm}$ and 620-720 nm dual channel emission. First, we examined lipid raft organization in the course of fiber development. The GP values were high in the fiber elongation stage (5-10 DPA, days past anthesis) and relatively low in the initial (0 DPA), secondary cell wall synthesis (20 DPA), and stable synthesis (30 DPA) stages. The GP value peaked in the 10 DPA fiber, and the value in 30 DPA fiber was the lowest. Furthermore, we examined the differences in lipid raft activity in fiber cells between the short fiber cotton mutant, $L i-1$, and its wild-type. The GP values of the $L i-1$ mutant fiber were lower than those of the wild type fiber at the elongation stage, and the GP values of 10 DPA fibers were lower than those of 5 DPA fibers in the Li-1 mutant.
\end{abstract}

Conclusions: We established a system for examining membrane lipid raft activity in cotton fiber cells. We verified that lipid raft activity exhibited a low-high-low change regularity during the development of cotton fiber cell, and the pattern was disrupted in the short lint fiber $\mathrm{Li}-1$ mutant, suggesting that membrane lipid order and lipid raft activity are closely linked to fiber cell development.

Keywords: Cotton fiber, Lipid raft, Di-4-ANEPPDHQ

\section{Background}

Cotton is the premier natural fiber for textiles. Cotton fibers are highly elongated single cells of the seed epidermis. The unicellular extremely elongated structure makes cotton fiber cell an ideal model for studying plant cell growth (Kim and Triplett 2001; Shi et al. 2006; Singh et al. 2009a;

\footnotetext{
*Correspondence: luo0424@126.com

${ }^{+} \mathrm{Xu} F$ and Suo XD contributed equally to this work.

Key Laboratory of Biotechnology and Crop Quality Improvement, Ministry of Agriculture/Biotechnology Research Center, Southwest University, Chongqing 400716, China
}

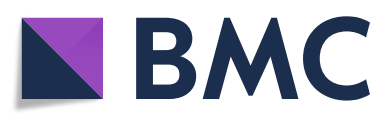

(อ The Author(s). 2020 Open Access This article is licensed under a Creative Commons Attribution 4.0 International License, which permits use, sharing, adaptation, distribution and reproduction in any medium or format, as long as you give

appropriate credit to the original author(s) and the source, provide a link to the Creative Commons licence, and indicate if changes were made. The images or other third party material in this article are included in the article's Creative Commons licence, unless indicated otherwise in a credit line to the material. If material is not included in the article's Creative Commons licence and your intended use is not permitted by statutory regulation or exceeds the permitted use, you will need to obtain permission directly from the copyright holder. To view a copy of this licence, visit http://creativecommons.org/licenses/by/4.0/ fiber consists of five distinctive but overlapping stages: initiation, elongation, transition, secondary cell wall deposition, and maturation (Haigler et al. 2012). Lint fiber initiates elongation near the day of anthesis and continues up to approximately 21 days post anthesis (DPA). During this period, the elongation rate exhibits a slow-fast-slow regularity. The elongation rate reaches a peak in approximate $10 \mathrm{DPA}$, and the fibers finally grow to $30-40 \mathrm{~mm}$ length (Liu et al. 2012). Subsequently, the elongation of fiber cells completely stops, and the fibers enters a stable 
secondary wall deposition period (20-45 DPA) (Singh et al. 2009b), followed by a dehydration period (45-50 DPA), which generates mature fibers.

Extremely elongated fiber cells require change in cell turgor pressure, plasmodesmatal regulation, and transporter activities (Ruan et al. 2004; Zhu et al. 2003). A large-scale transcriptome analysis revealed that during fiber cell elongation, lipid metabolism pathways are upregulated significantly (Gou et al. 2007). According to a cotton lipid spectrum analysis, the amount of unsaturated fatty acids in elongation stage fiber cells ( $\alpha$-linolenic acid: C18:3) is greater than that in ovules, and the amount of very-long-chain fatty acids (VLCFAs, from C20 to C26) eventually increases to three to five times (Wanjie et al. 2005). In addition, treating in vitro cultured cotton ovules with VLCFAs can promote the elongation of cotton fibers significantly, while treating with VLCFAs inhibitor acephrachlor (ACE) completely inhibits fiber growth, indicating that VLCFAs are involved in the cotton fiber elongation process (Qin et al. 2007). The study on $\Delta 12$ fatty acid desaturase revealed that the formation of unsaturated fatty acids under cold stress could maintain the specific membrane structure required for fiber elongation (Kargiotidou et al. 2008). Furthermore, plant-specific glycosylphosphatidylinositol (GPI) anchoring protein encoded gene COBL influences the orientation and crystallinity of fiber microfilaments, and is closely linked to fiber development (Roudier et al. 2010; Niu et al. 2019). During the rapid elongation stage, high phytosterol concentrations were also observed. In addition, numerous plant sterol biosynthesis genes were down-regulated in the short fiber of the $L i-1$ mutant, indicating that plant sterol also participates in the development of cotton fiber (Deng et al. 2016). VLCFAs are some of the substrates required for the synthesis of sphingolipids, and GPI is a precursor in the synthesis of complex sphingolipids. Sphingolipids and sterols are critical structural components of cell membranes, organelle membranes, and vacuolar membranes, and they form membrane lipid rafts (Hill et al. 2018). The relationship between the substances and fiber development indicates that the fiber membrane plays an important role in fiber development. However, the roles of membrane lipid raft in the development of cotton fiber remain unclear.

Fluorescent probes have been extensively used as biomarkers in biological studies. Laurdan and di-4-ANEPPDHQ are two phase-sensitive membrane probes and they respond uniquely to lipid packing, in a manner different from membrane associated peptides (Dinic et al. 2011). Laurdan and di4-ANEPPDHQ display blue shifts of approximately $50 \mathrm{~nm}$ in their emission peaks for membranes in liquid-ordered (lo) phase relative to membranes in liquid-disordered (ld) phase (Jin et al. 2005; Jin et al. 2006), and can be quantified by calculating the generalized polarization (GP) values (Aron et al.
2017). Laurdan is a type of ultra violet-excited dye that is usually imaged using a two-photon excited fluorescence (TPF) microscope to avoid the photobleaching tendency observed under single-photon excitation (Jin et al. 2005). The peak emission spectrum of Laurdan has been reported to be at $440 \mathrm{~nm}$ for lo phase and $490 \mathrm{~nm}$ for ld phase (Dinic et al. 2011). Di-4-ANEPPDHQ is a single photon excited dye, and its spectrum range is in the $500-750 \mathrm{~nm}$, covering the entire spectral range of most microscope systems (Owen and Gaus 2010), while the spectrum blue shift of the di-4-ANEPPDHQ dye is $60 \mathrm{~nm}$ (Aron et al. 2017). Quantitative in vivo imaging of lipid raft using di-4-ANEPPDHQ in artificial membrane systems and animal cells is well established (Owen et al. 2006; Owen and Gaus 2010; Owen et al. 2012). A few studies have mentioned the application of di-4-ANEPPDHQ in the visualization of plasma membrane microdomains in plant cells (Roche et al. 2008; Liu et al. 2009; Zhao et al. 2015).

\section{Materials and methods \\ Plant materials}

Wild-type Jimian 14 (Gossypium hirsutum L. cv. Jimian 14) was provided by professor MA Zhiying (Hebei Agricultural University) and was propagated and preserved at the Biotechnology Research Center of Southwest University. Short fiber cotton mutant Ligon lintless (Li-1) was provided by the Institute of Cotton Research, Chinese Academy of Agricultural Sciences, and the corresponding wild type (TM-1) for Li-1 mutant was segregated from a heterozygous $L i-1$ mutant. All plants were grown under natural conditions in the experimental field of the Biotechnology Research Center of Southwest University in Chongqing.

\section{In vitro cotton ovule culture}

Cotton ovules were collected 1 day after flower opening (defined as $1 \mathrm{DPA}$ ), soaked in $75 \%$ ethanol for $1 \mathrm{~min}$, rinsed in distilled and deionized water, and soaked again in $0.1 \%(\mathrm{~W} / \mathrm{V}) \mathrm{HgCl}$ solution containing $0.05 \%$ Tween80 at $100 \mathrm{~g}$ for $10 \mathrm{~min}$ to sterilize. Ovules were placed in Beasley and Ting's medium under aseptic conditions (Beasley and Ting 1973).

\section{Di-4-ANEPPDHQ staining}

Di-4-ANEPPDHQ was purchased from Invitrogen (CAT \#D36802). The stock solution of di-4-ANEPPDHQ [5 $\mathrm{mmol} \cdot \mathrm{L}^{-1}$ in dimethyl sulphoxide (DMSO)] was stored in dark at $-20^{\circ} \mathrm{C}$. For di-4-ANEPPDHQ staining, the in vitro cultured cotton ovules were incubated in staining solution as described in Results.

\section{Confocal laser scanning microscope observation}

An SP8 confocal laser scanning microscope (SP8 CLSM, Leica, Germany) was used for the imaging of di-4ANEPPDHQ-labelled cotton fibers. The sample was 
excited using a 488-nm laser, and the emission spectra were $500-580 \mathrm{~nm}$ (green) and $620-720 \mathrm{~nm}$ (red). A 63× oil immersion objective (N.A. $=1.3$ ) was used in this study. Identical microscope settings were maintained for quantitative imaging of membrane components.

\section{GP processing}

After CLSM imaging, generalized polarization (GP) images were generated by a previously described protocol (Owen et al. 2012), with some modifications. Briefly, the GP values were calculated according to the following equations:

$$
\begin{aligned}
& \mathrm{GP}=\left(\mathrm{I}_{500-580}-\mathrm{G} \times \mathrm{I}_{620-720}\right) /\left(\mathrm{I}_{500-580}+\mathrm{G} \times \mathrm{I}_{620-720}\right) \\
& \mathrm{G}=\left(\mathrm{GP}_{\text {ref }}+\mathrm{GP}_{\text {ref }} \mathrm{GP}_{\text {mes }}-\mathrm{GP}_{\text {mes }}-1\right) /\left(\mathrm{GPmes}+\mathrm{GP}_{\text {ref }} \mathrm{GPmes}-\mathrm{GP}_{\text {ref }}-1\right)
\end{aligned}
$$

I indicates the fluorescence intensity of each pixel of the image obtained within the receiving range of the two channels; $\mathrm{G}$ is the calibration constant; $\mathrm{GP}_{\text {mes }}$ is the calibrated GP value of di-4-ANEPPDHQ in pure DMSO solution with similar device parameters; when the ordered phase and the disordered phase are separated, $\mathrm{GP}_{\text {ref }}=0$. The fluorescence intensity value of each image was calculated using Image J 1.46 (https://imagej.nih.gov/ij/ download.html).

\section{Ratio image processing}

Dual-channel ratio imaging (ratio) can be used for quantitative analysis of membrane organization (Jin et al. 2005). In the present study, fluoviewFV1000 was used for ratio imaging of di-4-ANEPPDHQ stained cotton fiber cells. The formula for calculating ratio images is as follows:

$$
\text { Ratio }_{\mathrm{r} / \mathrm{g}}=\left(\text { int }_{\mathrm{r}}-\mathrm{bkg}_{\mathrm{r}}\right) /\left(\text { int }_{\mathrm{g}}-\mathrm{bkg}_{\mathrm{g}}\right) \times \mathrm{MF}
$$

int $_{\mathrm{r}}$ and int $\mathrm{g}_{\mathrm{g}}$ represent the fluorescence intensities of red channel and green channel images, respectively; $b_{k g}$ and $b_{k g}$ represent the background values set for int ${ }_{r}$ and int $t_{\mathrm{g}}$, respectively; the background values are set similarly to avoid interference. MF is the multiplication factor.

\section{Results}

Di-4-ANEPPDHQ is a low toxicity fluorescent probe dye for cotton fibers

During the growth and development of cotton fiber cells, the changes in cell morphology are closely related to the cell membrane. Considering di-4-ANEPPDHQ is used as probe for detecting membrane order. In the present study, we use the fluorescent dye to detect the membrane lipid raft organization in cotton fiber cells. First, we investigated the toxicity of di-4-ANEPPDHQ to cotton fiber growth and development. Following exogenous application of di-4-ANEPPDHQ at various concentrations, we observed that the lengths of di-4-ANEPPDHQtreated cotton fibers were similar to those of untreated fibers after culture for similar periods (Fig. 1). The results indicated that di-4-ANEPPDHQ is a low toxicity fluorescent probe for cotton fiber and could be used for the observing of lipid raft microregions of cotton fiber cells.

The fluorescence emission spectra of di-4-ANEPPDHQ in cotton fibers

Di-4-ANEPPDHQ is a fluorescent probe that responds rapidly to changes in electric potential in the environment.

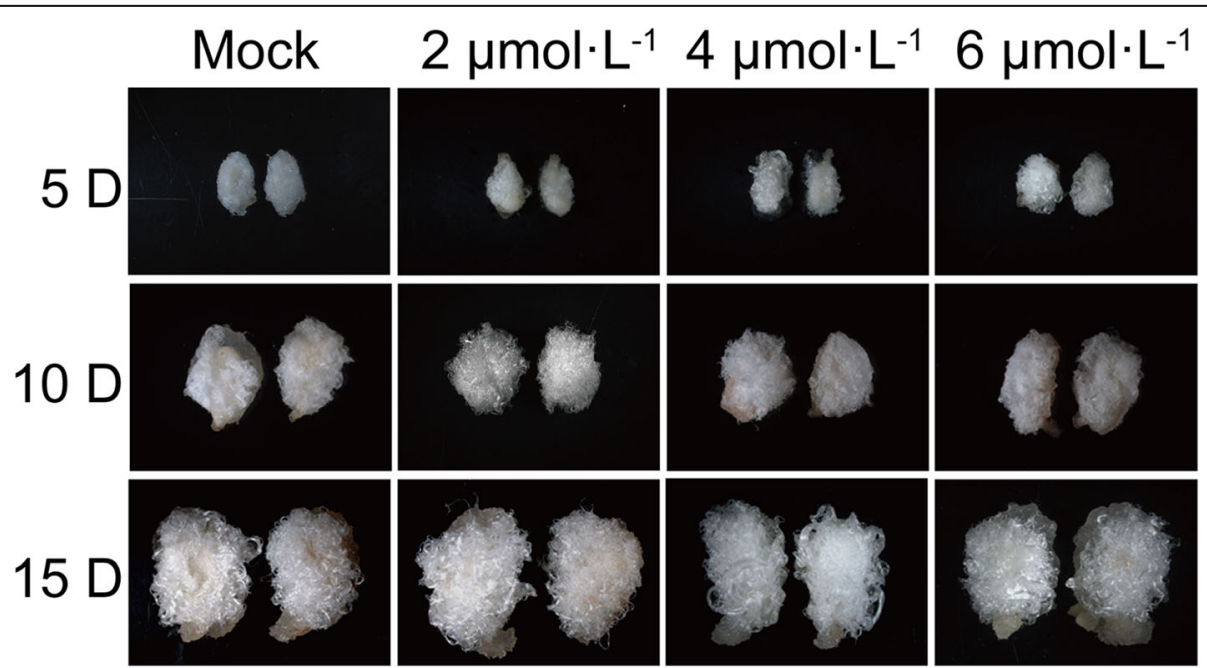

Fig. 1 Effects of di-4-ANEPPDHQ on the growth of cotton fiber cells. Cotton ovules were treated with $0 \mu \mathrm{mo}\left|\cdot \mathrm{L}^{-1}, 2 \mu \mathrm{mol} \cdot \mathrm{L}^{-1}, 4 \mu \mathrm{mo}\right| \cdot \mathrm{L}^{-1}$, $6 \mu \mathrm{mol} \cdot \mathrm{L}^{-1}$ di-4-ANEPPDHQ and cultured in vitro for 5 day, 10 day and 15 day 
Its spectral characteristics are related to environment, cell type, and electric potential. To determine the spectral characteristics of di-4-ANEPPDHQ in fiber cells, we used excitation light at $488 \mathrm{~nm}$ to collect emission spectra at $10-\mathrm{nm}$ intervals in a lambda acquisition mode and calculated the spectral intensity. The range of emission fluorescence intensity of di-4-ANEPPDHQ-dyed cotton fiber cells was 550-660 $\mathrm{nm}$ and the peak emission fluorescence intensity was observed at $580 \mathrm{~nm}$ (Fig. 2).

\section{The optimum labeling conditions of di-4-ANEPPDHQ for cotton fibers}

Considering di-4-ANEPPDHQ is a very sensitive fluorescent probe, treatment time and concentrations are two key factors to be taken into account in the application of the dye. To determine the optimal labeling conditions for di-4-ANEPPDHQ for dyeing cotton fibers, we examined the fluorescence of di-4-ANEPPDHQ-stained fiber cells under different concentrations and treatment times. When the staining time was $3 \mathrm{~min}$, the fluorescence signal could hardly be detected under the low concentration treatments (Fig. 3a), while treatment for $5 \mathrm{~min}$ with $3 \mu \mathrm{mol} \cdot \mathrm{L}^{-1}$ di-4-ANEPPDHQ, yielded fluorescence images could be recorded (Fig. $3 \mathrm{~b}$ ). Therefore, we selected $3 \mu \mathrm{mol} \cdot \mathrm{L}^{-1}$ and $5 \mathrm{~min}$ treatment as the optimal labeling conditions for staining cotton fiber cells using di-4ANEPPDHQ.

\section{Membrane lipid raft order of wild-type cotton fibers}

To understand the change regularity in plasma membrane lipid raft organization in the course of the development of cotton fiber cells, we detected the fluorescence signals at 0 DPA, 5 DPA, 10 DPA, 20 DPA, and 30 DPA, in fiber cells stained with di-4-ANEPPDHQ. The fluorescence intensity of the green channel (liquid-ordered phase, 500-580 nm) was stronger at 0 DPA, 5 DPA, and 10 DPA fibers, but weaker at 20 DPA and 30 DPA. Conversely, the fluorescence intensity of the red channel (liquid-disordered phase, $620-720 \mathrm{~nm}$ ) was weaker in 0 DPA, 5 DPA, and 10 DPA fibers, but stronger in 20 DPA and 30 DPA fibers (Fig. 4). The results indicated that the plasma membrane order was higher at the early stages of fiber development, while the plasma membrane is disorder at the later stages of fiber development. Furthermore, the ratio (red/green) of the double channel fluorescence intensity was plotted, and the white color indicated that the membrane order and the lipid raft activity were low, while the blue color represented higher membrane order and lipid raft activity. The ratio images indicated that the fiber membranes at 0 DPA were almost all white and red; the blue were the highest at 10 DPA, with almost no distribution of white dot; the fiber membranes had a certain amount of white distribution at 20 DPA; the fiber membranes were almost all white at 30 DPA (Fig. 4). These suggested that at the initiation stage, the lipid order of fiber cell membrane and
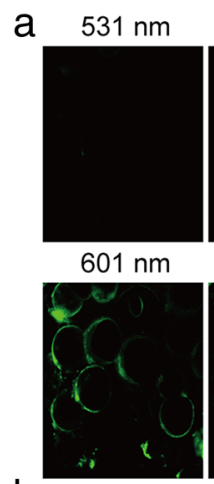

b
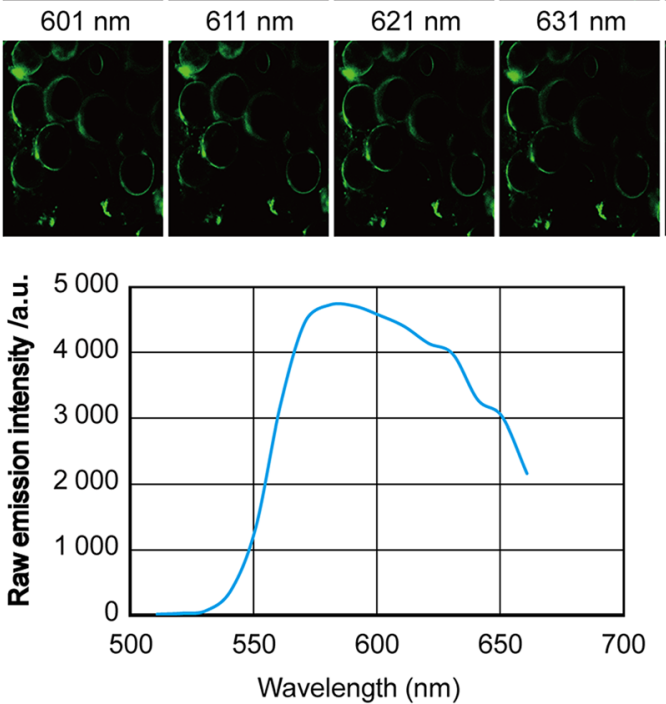
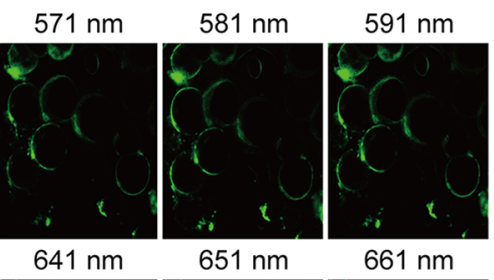

$651 \mathrm{~nm}$
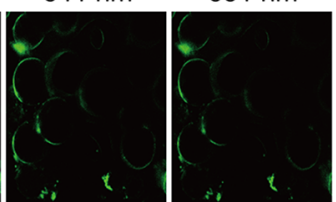

$661 \mathrm{~nm}$
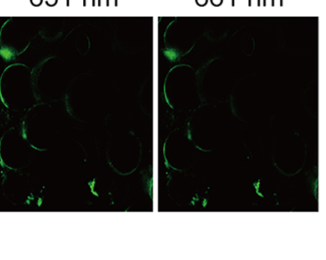

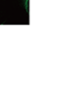



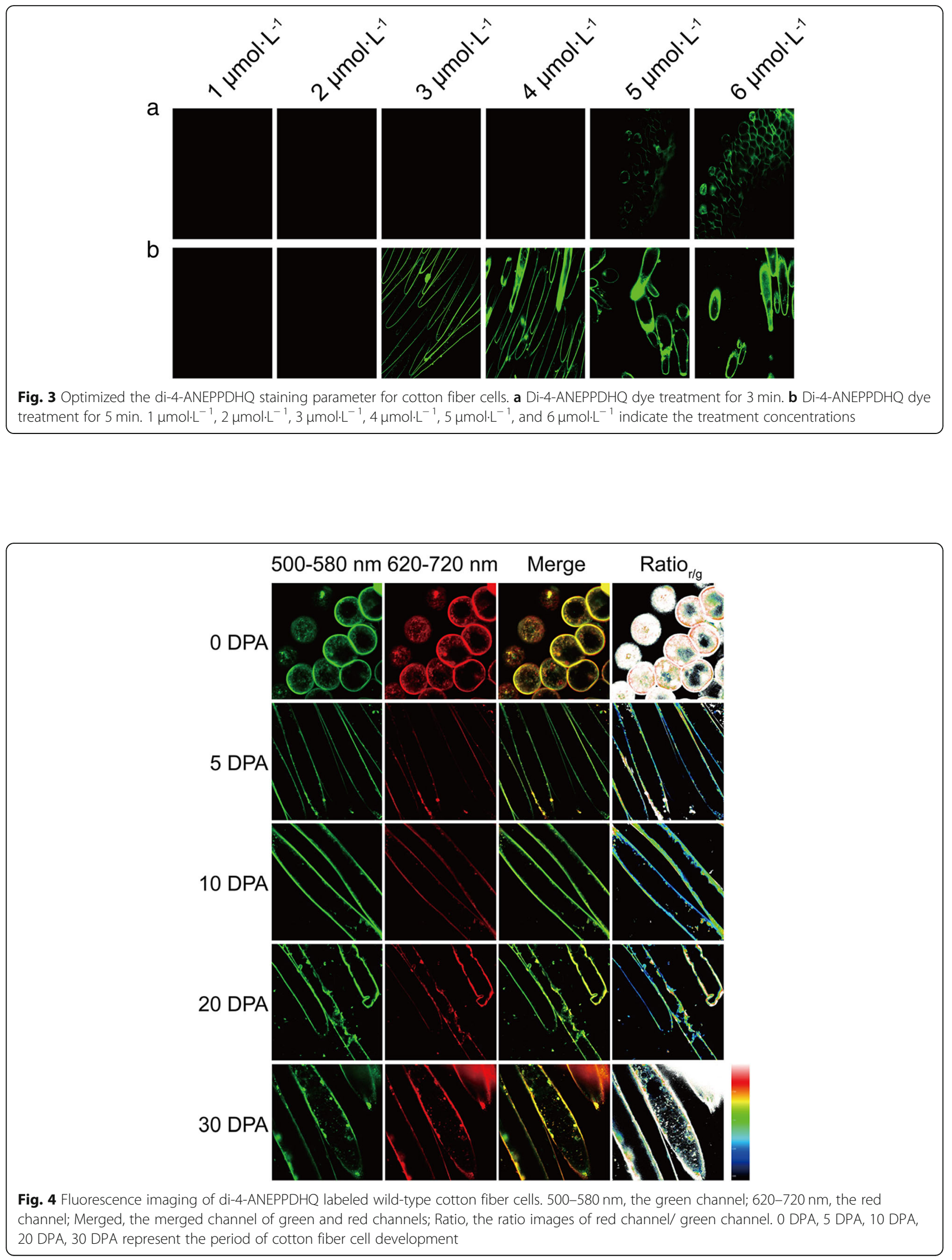
the lipid raft activity were lower, and the fiber cell membrane lipid order and lipid raft activity increased gradually as the fibers transitioned into the rapid elongation stage. In addition, with the termination of fiber cell elongation, fiber cells entered the secondary wall synthesis phase, and fiber cell membrane lipid order and lipid raft activity decreased. Therefore, during cotton fiber cell development, membrane lipid order and lipid raft activity change from low to high, then to low, and the physiological and biochemical activities of fiber cells were the greatest in elongation phase.

For quantitative analysis of the obtained pictures, we calculated the generalized polarization (GP) values and red/green ratio $\left(\mathrm{Ratio}_{\mathrm{r} / \mathrm{g}}\right.$ ) values based on more images. The GP values in fiber cells at 0 DPA were relatively lower. With the development of fiber cells, the GP values increased gradually, reaching the peak at 10 DPA, and then decreased to the lowest level at 30 DPA (Fig. 5a). The results are consistent with the fluorescence signal observations, which also indicated that the fiber cell membrane lipid order and lipid raft activity were higher at the rapid elongation stage, and lower in the secondary wall synthesis phase. The Ratio ${ }_{\mathrm{r} / \mathrm{g}}$ value in the $10 \mathrm{DPA}$ fiber cells was $0.557 \pm 0.131$, which was the lowest value observed in the course of fiber development. Conversely, the value was $1.410 \pm 0.090$ at $30 \mathrm{DPA}$, which was the highest value observed in the course of fiber development (Fig. 5a). The results suggest that the lipid raft activity, cell membrane order, and physiological activity of fiber cells were the greatest during the rapid elongation phase.

\section{Membrane lipid raft order of Li-1 mutant cotton fibers}

To further verify the relationship between lipid raft activity and fiber cell elongation development, we examined changes in GP value during the elongation of fiber cells of a short fiber mutant, Ligon lintless-1 (Li-1). Notably, the GP value in $L i-1$ mutant fibers was remarkably lower than the GP values in wild-type fibers at the similar development stages (Fig. 6), indicating that lipid raft activity was lower in mutant fiber cells. In addition, the GP value in wild-type fibers increased from 5 DPA to 10 DPA, while the GP value in mutant fibers decreased from 5 DPA to 10 DPA (Fig. 6), which further indicated that membrane lipid order and lipid raft activity were closely correlated with cotton fiber development.

\section{Discussion}

Biomembranes play an important role in cell growth and development. The cotton fiber cell is one of the longest cells in plants. Owing to its highly elongated structure and high cellulose content, the cotton fiber serves as an excellent system for studying cell elongation, cell wall formation, and other fundamental aspects of plant cell growth and development (Kim and Triplett 2001).Therefore, it is assumed that membrane also play an important role in fiber growth. On the one hand, with the expansion of cell size, the area of the plasma membrane and the inner membrane needs to increase correspondingly; conversely, it serves as the site of attachment of most enzymes (about $80 \%$ of the enzymes are membranebinding proteins, for example, the cellulose synthase complex is located in the plasma membrane). However, studying membrane functions and properties is challenging due to its dynamic structure and limited technologies. In recent years, following advancements in technologies, researchers have demonstrated that lipid rafts (lipid microdomains) are the functional domains of membranes using diverse approaches (Mongrand et al. 2004; Borner et al. 2005).

Plasma membranes (PMs) are composed of three major classes of lipids, including glycerolipids, sphingolipids, and
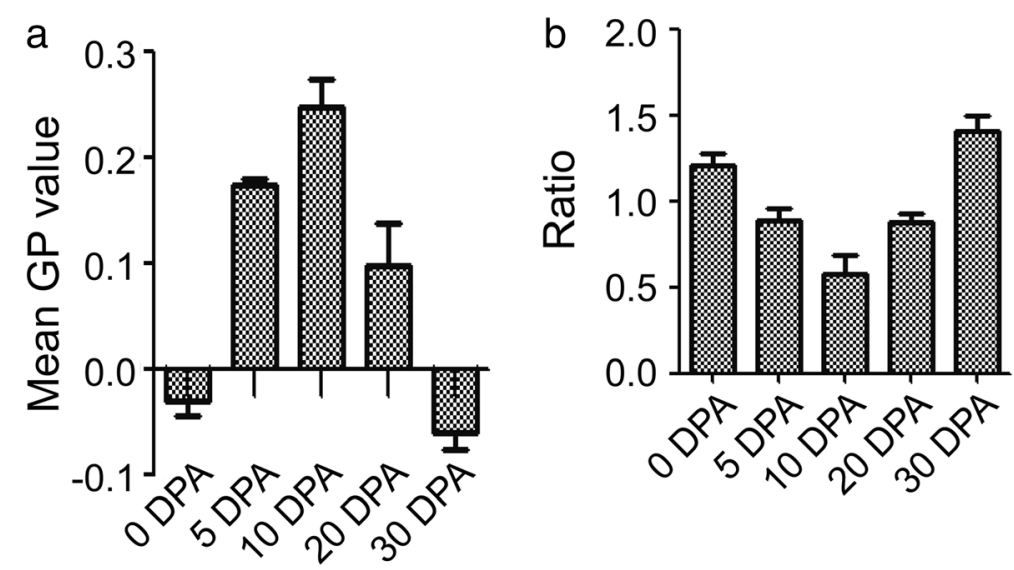

Fig. 5 The GP and Ratio value of wild-type cotton fiber. a The GP value of 0 DPA, 5 DPA, 10 DPA, 20 DPA, and 30 DPA wild-type cotton fibers. $\mathbf{b}$ The Ratio $_{\mathrm{r} / \mathrm{g}}$ value statistics of 0 DPA, 5 DPA, 10 DPA, 20 DPA, 30 DPA wild-type cotton fibers 


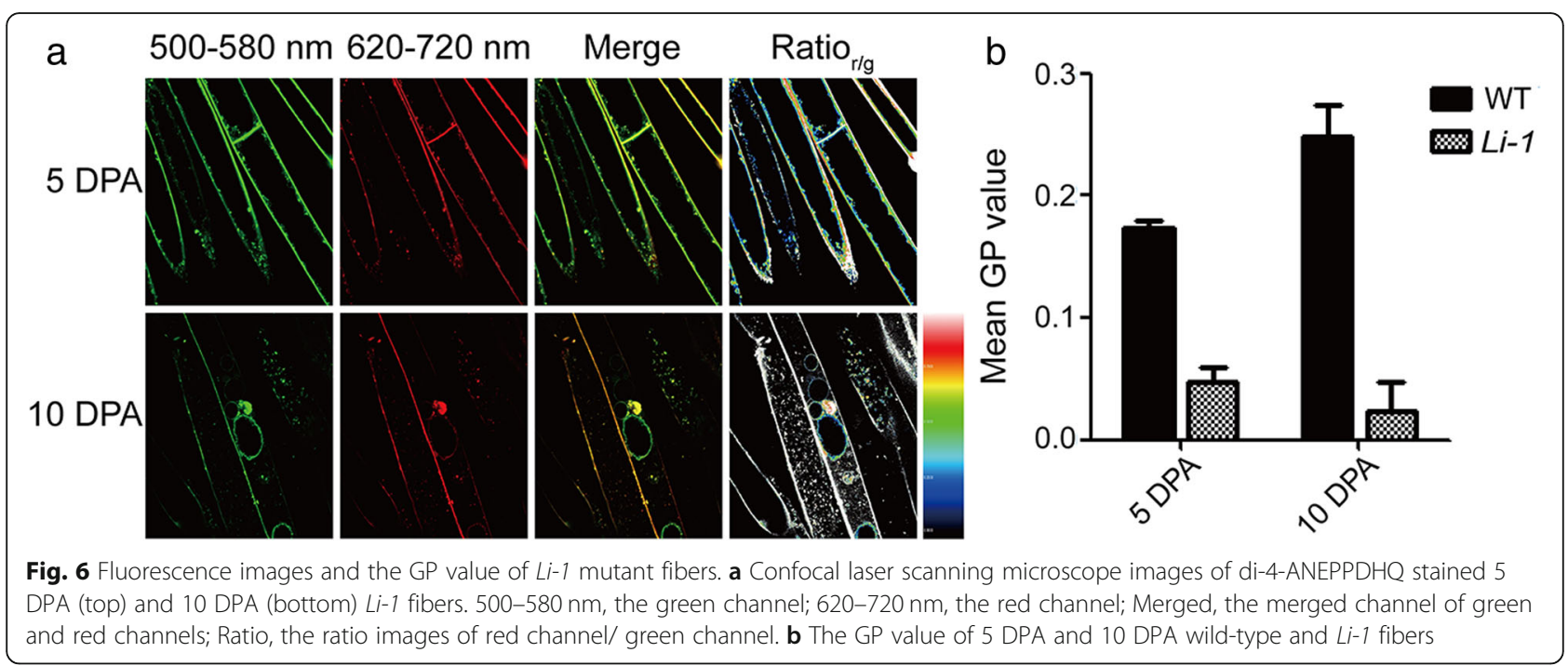

sterols, which may account for up to 100000 distinct molecular species (Yetukuri et al. 2008; Shevchenko and Simons 2010). Overall, all glycerolipids share similar molecular moieties in plants, animals, and fungi. In contrast, sterols and sphingolipids are varied and specific to each kingdom, and are the major components of lipid rafts (Cacas et al. 2016). Membrane lipid raft activity has become a major index for characterizing membrane properties. Higher order cell membranes and higher lipid raft activity could offer stable reaction platforms and ordered dynamic environment for various physiological and biochemical reactions (Maccioni et al. 2002; Yu et al. 2004), which are closely linked to the polar elongation of cells (Meder et al. 2006; Sorek et al. 2007; Cánovas and PérezMartín 2009). Over the last two decades, considerable progress has been made in cotton fiber studies. The components of lipid raft have been verified to play a key role in fiber development. For example, VLCFAs are required for fiber development and mainly served as precursors of sphingolipid biosynthesis (Qin et al. 2007). In addition, the compositions and concentrations of plant sterols influence fiber growth (Deng et al. 2016; Niu et al. 2019). Furthermore, it has been demonstrated that inhibiting sphingolipid synthesis seriously suppresses fiber cell growth. The results indicate that lipid rafts play a key role in the development of fiber cells. Therefore, it is critical to examine membrane lipid raft activity during fiber development.

The fluorescence probe di-4-ANEPPDHQ could bind both liquid-order (lo) and liquid-disorder (ld) phase membranes. Due to its strong polarity-dependent spectral shifts, di-4-ANEPPDHQ could stain lo and ld phase membranes in different colors (Klymchenko and Kreder 2014). Through fluorescence lifetime imaging and CLSM, the optical properties of di-4-ANEPPDHQ in animal cells have been well studied and applied to detect lipid raft activity in living cells (Owen et al. 2006, 2012). However, few studies that focus on plant cells have been performed. Roche et al. (2008) used the dye to explore changes in membrane lipid activity in BY2 cells following treatment with plant sterol chelate- $\beta$-cyclodextrin, and they demonstrated that the sterol influenced lipid raft activity significantly in plant cells. Liu et al. (2009) used di-4-ANEPPDHQ to investigate the aggregation of lipid micro area (lipid raft) at the tip of a pollen tube in Picea meyeri, which is analogous to the polar elongation of the pollen tube. In addition, Zhao et al. (2015) studied root epidermal cell and root hair cell using di-4ANEPPDHQ in Arabidopsis, and reported that the ordered degree of plasma membrane was higher than that of the inner membrane in root epidermal and root hair cells.

In the present study, we investigated the toxicity and optical properties of di-4-ANEPPDHQ to cotton fiber cell. The toxicity of the di-4-ANEPPDHQ to fiber cell was relatively low. Furthermore, there was no obvious difference in fiber cell elongation between the fiber treated with $6 \mu \mathrm{mol} \cdot \mathrm{L}^{-1} \mathrm{di}-4$-ANEPPDHQ and the control, which is similar to the results observed in root hair cells (Zhao et al. 2015). In the fiber cell, incubation with 3 $\mathrm{mmol} \cdot \mathrm{L}^{-1}$ of the di-4-ANEPPDHQ probe in the culture medium for $5 \mathrm{~min}$ at room temperature was adequate, while for root epidermal cells and root hairs, incubation with $5 \mathrm{mmol} \cdot \mathrm{L}^{-1}$ of the di-4-ANEPPDHQ probe in the culture medium for $5 \mathrm{~min}$ at room temperature was adequate (Zhao et al. 2015). The results suggested that the optimal stain condition depended on the materials.

Changes in lipid raft activity in the plasma membrane were observed in the course of fiber cell development. In addition, the rapid elongation phase of the fiber cell exhibited higher lipid raft activity, while the elongation termination and the early elongation stages exhibited 
relatively low lipid raft activity, which showed that lipid raft activity of the plasma membrane and plasma membrane organization were closely related to fiber cell elongation. Phytosterol is one of components of lipid raft. During fiber growth, higher concentrations of sitosterol and campesterol, two major phytosterols, were detected in the rapid elongation phase fiber cells, when compared with the concentrations in the early fiber elongation and secondary cell wall deposition stages (Deng et al. 2016). The change in trends of membrane lipid raft activity was consistent with the phytosterol concentration trends oberserved in the course of fiber cell development. Roche et al. (2008) used cyclic oligosaccharide methyl- $\beta$-cyclodextrin, commonly used in animal cells to decrease cholesterol levels, to induce a drastic reduction (50\%) in the total free sterol concentrations in PM of BY2 cells and the depletion of sterol concentrations increased lipid acyl chain disorder. The results confirm that higher phytosterol concentrations are associated with higher membrane lipid raft activity (membrane order). Since phytosterols and sphingolipids are two key components of lipid raft, further studies should focus on the role of sphingolipids and various molecule species of phytosterols or sphingolipids on lipid raft activity in the cotton fiber cell.

\section{Conclusion}

In the present study, we investigated lipid raft activity in cotton fiber cell during its developmental process by labeling it with di-4-ANEPPDHQ. Using an in vitro cotton ovule culture system, we verified that the dye exhibited low toxicity to cotton fiber, and we established the optimal labeling conditions of the dye for the cotton fiber plasma membrane as follows: incubation with $3 \mu \mathrm{mol} \cdot \mathrm{L}^{-1}$ of the di-4-ANEPPDHQ probe for $5 \mathrm{~min}$ at room temperature. Based on the phase separation characteristics of di-4-ANEPPDHQ, dual channel images were obtained using CLSM (Leica SP8) and were processed based on GP values and a Ratio ${ }_{\mathrm{r} / \mathrm{g}}$ processing algorithm. According to the results, the membrane order degrees of cotton fiber cell exhibited a low-high-low change regularity with the development of cotton fiber cell. In addition, the regularity was disrupted in the short lint fiber Li-1 mutant. Overall, the results imply that there is a close relationship between cotton fiber cell development and cell membrane lipid organization and lipid raft activity.

\section{Abbreviations}

ACE: Acephrachlor; CLSM: Confocal laser scanning microscope; DMSO: Dimethyl sulfoxide; DPA: Days post anthesis; GP: Generalized polarization; Li-1: Ligon lintless-1; Id: Liquid disorder; lo: Liquid order; MF: Multiplication factor; VLCFA: Very-long-chain fatty acid

\section{Acknowledgments}

We are grateful to Professor MA Zhiying (Hebei Agricultural University) for kindly providing the Jimian 14 seeds. We thank the Institute of Cotton Research, Chinese Academy of Agricultural Sciences for providing the Li-1 mutant seeds.

\section{Authors' contributions}

SX and XF performed most of the experiments. LF, BC, HS, HL performed some of the experiments. LM designed the experiments. XF and LM analyzed the data and wrote the manuscript. SX and XF performed most of the experiments. $L F, B C, H S$, $H L$ performed some of the experiments. $L M$ designed the experiments. XF and LM analyzed the data and wrote the manuscript. The author(s) read and approved the final manuscript.

\section{Funding}

This work was financially supported by the National Natural Science Foundation of China (31571722 and 31971984), the Funds for Creative Research Groups of China (31621005), and the Genetically Modified Organisms Breeding Major Project of China (No. 2018ZX0800921B). The funding bodies did not play any role in the design of the study and collection, analysis, and interpretation of data or in writing the manuscript.

Availability of data and materials

Not applicable.

Ethics approval and consent to participate

Not applicable.

Consent for publication

Not applicable.

\section{Competing interests}

The authors have declared that no competing interests exist.

Received: 4 February 2020 Accepted: 16 April 2020

Published online: 19 May 2020

\section{References}

Aron M, Browning R, Carugo D, et al. Spectral imaging toolbox: segmentation, hyperstack reconstruction, and batch processing of spectral images for the determination of cell and model membrane lipid order. BMC Bioinformatics. 2017;18(1):254. https://doi.org/10.1186/s12859-017-1656-2.

Beasley CA, Ting IP. The effects of plant growth substances on in vitro fiber development from fertilized cotton ovules. Am J of Botany. 1973;60(2):130-9. https://doi.org/10.1002/j.1537-2197.1973.tb10209.x.

Borner GH, Sherrier DJ, Weimar T, et al. Analysis of detergent-resistant membranes in Arabidopsi. Evidence for plasma membrane lipid rafts. Plant Physiol. 2005;137:104-16. https://doi.org/10.1104/pp.104.053041.

Cánovas D, Pérez-Martín J. Sphingolipid biosynthesis is required for polar growth in the dimorphic phytopathogen Ustilago maydis. Fungal Genet Biol. 2009; 46(2):190-200. https://doi.org/10.1016/j.fgb.2008.11.003.

Deng S, Wei T, Tan K, et al. Phytosterol content and the campesterol:sitosterol ratio influence cotton fiber development: role of phytosterols in cell elongation. Sci China Life Sci. 2016;59(2):183-93. https://doi.org/10.1007/ s11427-015-4992-3.

Dinic J, Biverståhl H, Mäler L, Parmryd I. Laurdan and di-4-ANEPPDHQ do not respond to membrane-inserted peptides and are good probes for lipid packing. Biochim Biophys Acta. 2011;1808(1):298-306. https://doi.org/10. 1016/j.bbamem.2010.10.002.

Gou JY, Wang $L$, Chen SP, et al. Gene expression and metabolite profiles of cotton fiber during cell elongation and secondary cell wall synthesis. Cell Res. 2007;17(5):422-34. https://doi.org/10.1038/s..cr.7310150.

Haigler $\mathrm{CH}$, Betancur L, Stiff MR, Tuttle JR. Cotton fiber: a powerful single-cell model for cell wall and cellulose research. Front Plant Sci. 2012;3:104. https:// doi.org/10.3389/fpls.2012.00104.

Hill CH, Cook GM, Spratley SJ, et al. The mechanism of glycosphingolipid degradation revealed by a GALC-SapA complex structure. Nat Commun. 2018;9:151. https://doi.org/10.1038/s41467-017-02361-y.

Cacas JL, Buré C, Grosjean K, et al. Revisiting plant plasma membrane lipids in tobacco: a focus on sphingolipids. Plant Physiol. 2016;170:367-84. https://doi. org/10.1104/pp.15.00564. 
Jin L, Millard AC, Wuskell JP, et al. Cholesterol-enriched lipid domains can be visualized by di-4-ANEPPDHQ with linear and nonlinear optics. Biophys J. 2005;89(1):L4-6. https://doi.org/10.1529/biophysj.105.064816.

Jin L, Millard AC, Wuskell JP, et al. Characterization and application of a new optical probe for membrane lipid domains. Biophys J. 2006;90(7):2563-75. https://doi.org/10.1529/biophysj.105.072884.

Kargiotidou A, Deli D, Galanopoulou D, et al. Low temperature and light regulate delta 12 fatty acid desaturases (FAD2) at a transcriptional level in cotton (Gossypium hirsutum). J Exp Bot. 2008;59(8):2043-56. https://doi.org/10.1093/ jxb/ern065.

Kim HJ, Triplett BA. Cotton fiber growth in planta and in vitro. Models for plant cell elongation and cell wall biogenesis. Plant Physiol. 2001;127(4):1361-6. https://doi.org/10.1104/pp.010724.

Klymchenko AS, Kreder R. Fluorescent probes for lipid rafts: from model membranes to living cells. Chem Biol. 2014;21(1):97-113. https://doi.org/10. 1016/j.chembiol.2013.11.009

Liu K, Sun J, Yao L, Yuan Y. Transcriptome analysis reveals critical genes and key pathways for early cotton fiber elongation in Ligon lintless-1 mutant. Genomics. 2012;100(1):42-50. https://doi.org/10.1016/j.ygeno.2012.04.007.

Liu P, Li RL, Zhang L, et al. Lipid microdomain polarization is required for NADPH oxidase-dependent ROS signaling in Picea meyeri pollen tube tip growth. Plant J. 2009;60(2):303-13. https://doi.org/10.1111/j.1365-313X.2009.03955.X.

Maccioni HJF, Giraudo CG, Daniotti JL. Understanding the stepwise synthesis of glycolipids. Neurochem Res. 2002;27(7-8):629-36. https://doi.org/10.1023/a: 1020271932760.

Meder D, Moreno MJ, Verkade P, et al. Phase coexistence and connectivity in the apical membrane of polarized epithelial cells. Proc Natl Acad Sci USA. 2006; 103(2):329-34. https://doi.org/10.1073/pnas.0509885103.

Mongrand S, Morel J, Laroche J, et al. Lipid rafts in higher plant cells purification and characterization of triton X-100-insoluble microdomains from tobacco plasma membrane. J Biol Chem. 2004;279:36277-86. https://doi.org/10.1074/ jbc.M403440200.

Niu Q, Tan K, Zang Z, et al. Modification of phytosterol composition influences cotton fiber cell elongation and secondary cell wall deposition. BMC Plant Biol. 2019;19(1):208. https://doi.org/10.1186/s12870-019-1830-y.

Owen DM, Gaus K. Optimized time-gated generalized polarization imaging of Laurdan and di-4-ANEPPDHQ for membrane order image contrast enhancement. Microsc Res Tech. 2010;73(6):618-22. https://doi.org/10.1002/ jemt.20801.

Owen DM, Lanigan PMP, Dunsby $C$, et al. Fluorescence lifetime imaging provides enhanced contrast when imaging the phase-sensitive dye di-4-ANEPPDHQ in model membranes and live cells. Biophys J. 2006;90(11):L80-2. https://doi. org/10.1529/biophysj.106.084673.

Owen DM, Rentero C, Magenau A, et al. Quantitative imaging of membrane lipid order in cells and organisms. Nat Protoc. 2012;7(1):24-35. https://doi.org/10. 1038/nprot.2011.419.

Qin YM, Hu CY, Pang Y, et al. Saturated very-long-chain fatty acids promote cotton fiber and Arabidopsis cell elongation by activating ethylene biosynthesis. Plant Cell. 2007;19(11):3692-704. https://doi.org/10.1105/tpc.107.054437.

Qin YM, Zhu YX. How cotton fibers elongate: a tale of linear cell-growth mode. Curr Opin Plant Biol. 2011;14(1):106-11. https://doi.org/10.1016/j. pbi.2010.09.010.

Roche Y, Gerbeau-Pissot P, Buhot B, et al. Depletion of phytosterols from the plant plasma membrane provides evidence for disruption of lipid rafts. FASEB J. 2008;22(11):3980-91. https://doi.org/10.1096/fj.08-111070.

Roudier F, Gissot L, Beaudoin F, et al. Very-long-chain fatty acids are involved in polar auxin transport and developmental patterning in Arabidopsis. Plant Cell. 2010;22(2):364-75. https://doi.org/10.1105/tpc.109.071209.

Ruan YL, Xu SM, White R, Furbank RT. Genotypic and developmental evidence for the role of plasmodesmatal regulation in cotton fiber elongation mediated by callose turnover. Plant Physiol. 2004;136(4):4104-13. https://doi.org/10. 1104/pp.104.051540.

Shevchenko A, Simons K. Lipidomics: coming to grips with lipid diversity. Nat Rev Mol Cell Biol. 2010;11:593-8. https://doi.org/10.1038/nrm2934.

Shi YH, Zhu SW, Mao XZ, et al. Transcriptome profiling, molecular biological, and physiological studies reveal a major role for ethylene in cotton fiber cell elongation. Plant Cell. 2006;18(3):651-64. https://doi.org/10.1105/tpc. 105.040303 .

Singh B, Avci U, Inwood SEE, et al. A specialized outer layer of the primary cell wall joins elongating cotton fibers into tissue-like bundles. Plant Physiology. 2009a;150(2):684-99. https://doi.org/10.1104/pp.109.135459.
Singh B, Cheek HD, Haigler CH. A synthetic auxin (NAA) suppresses secondary wall cellulose synthesis and enhances elongation in cultured cotton fiber. Plant Cell Rep. 2009b;28(7):1023-32. https://doi.org/10.1007/ s00299-009-0714-2.

Sorek N, Poraty L, Sternberg H, et al. Activation status-coupled transient S acylation determines membrane partitioning of a plant rho-related GTPase (retracted article. See vol 37, Artn e00321-17, 2017). Mol Cell Biol. 2007;27(6): 2144-54. https://doi.org/10.1128/MCB.02347-06.

Wanjie SW, Welti R, Moreau RA, Chapman KD. Identification and quantification of glycerolipids in cotton fibers: reconciliation with metabolic pathway predictions from DNA databases. Lipids. 2005;40(8):773-85. https://doi.org/10. 1007/s11745-005-1439-4.

Yetukuri L, Ekroos K, Vidal-Puig A, Oresic M. Informatics and computational strategies for the study of lipids. Mol BioSyst. 2008;4:121-7.

Yu RK, Bieberich E, Xia T, Zeng GC. Regulation of ganglioside biosynthesis in the nervous system. J Lipid Res. 2004;45(5):783-93. https://doi.org/10.1194/jlr. R300020-JLR200.

Zhao X, Li R, Lu C, et al. Di-4-ANEPPDHQ, a fluorescent probe for the visualisation of membrane microdomains in living Arabidopsis thaliana cells. Plant Physiol Biochem. 2015;87:53-60. https://doi.org/10.1016/j.plaphy.2014.12.015 .

Zhu YQ, Xu KX, Luo B, et al. An ATP-binding cassette transporter GhWBC1 from elongating cotton fibers. Plant Physiol. 2003;133(2):580-8. https://doi.org/10. 1104/pp.103.027052.

\section{Ready to submit your research? Choose BMC and benefit from:}

- fast, convenient online submission

- thorough peer review by experienced researchers in your field

- rapid publication on acceptance

- support for research data, including large and complex data types

- gold Open Access which fosters wider collaboration and increased citations

- maximum visibility for your research: over $100 \mathrm{M}$ website views per year

At BMC, research is always in progress.

Learn more biomedcentral.com/submissions 